\title{
Modal Epistemology Made Concrete
}

Many philosophers since Hume have accepted that imagining/conceiving a scenario is our prime guide to knowing its possibility. Stephen Yablo provided a more systematic criterion: one is justified in judging that $p$ is possible if one can imagine a world which one takes to verify $p$. I defend a version of Yablo's criterion against van Inwagen's moderate modal scepticism. Van Inwagen's key argument is that we cannot satisfy Yablo's criterion because we are not in a position to spell out far-fetched possible scenarios in relevant detail. Van Inwagen's argument can be applied to the use of conceivability for everyday possibility claims, leaving us with the spectre of pervasive modal scepticism. In order to answer the sceptical threat, I combine van Inwagen's main example with general considerations about the nature of metaphysical modality to motivate a version of Yablo's criterion and show that it does not lead to scepticism. One structural condition of $p$ being metaphysically possible is that it coheres with a complete reality. This condition gives rise to Yablo's criterion. However, for the criterion to be of any avail, we have to disregard details we are not in a position to specify. To account for our practice of doing so, I use Yablo's distinction between imagining a world as determinate and imagining it determinately. I present a condition when we may simply disregard details as determinate. The condition results from integrating analogical reasoning into the conceivability test.

Conceivabilism is one main strand in modal epistemology: we take something to be possible if we can conceive viz. imagine it. A certain qualified way of representing that $p$ justifies one's claim that $p$ is possible. This general idea is common to both camps in the historical 
divide of empiricism and rationalism, though there is considerable disagreement on what the qualified ways of representing are like (e.g. Descartes 1985, 299, Hume 1739-40, 1.2.2.8, 32).

In present debate, there are prominent supporters of conceivabilism. Stephen Yablo even contends: 'if there is a seriously alternative basis for possibility theses, philosophers have not discovered it' $(1993,2)$. This may seem exaggerated, given alternatives like modal rationalism (e.g. Bealer 2004), accounts based on conceptual knowledge (Peacocke 2004, Jenkins 2010), knowledge of essences (Lowe 2012), knowledge of counterfactuals (Williamson 2007), abduction (Biggs 2011) or a sui generis faculty of modalizing (Fiocco 2007), to mention only some. Some of these alternatives might be developed within or outside of the paradigm of conceivabilism.

Still conceivability evidence is often explicitly invoked in philosophical practice. It is used to support or question variegated claims to metaphysical possibility, for instance in modern classics like Kripke (1980), Putnam (1980, 29-30) or more recently in debates on the special composition question (Sider 1993, Williams 2006) and on cognitive phenomenology (Kriegel 2015). More generally, it seems that, if a philosopher not engaged in modal epistemology wishes to support a daring possibility claim, conceivability is an outstanding option. Hence scepticism about conceivability evidence threatens well-established philosophical practice.

Furthermore, conceivabilism promises a unified epistemology at least of metaphysical possibilities (I shall disregard the issue of knowing necessities in this article, cf. Hale 2002). Other things being equal, such a unified approach is more attractive than a piecemeal one. This is not to exclude that there are many roads to modal knowledge.

In sum, it seems a worthwhile endeavour to defend conceivabilism against sceptical threats. I shall attempt such a defence against a major challenge that has been intensely discussed in the last decades, Peter van Inwagen's (1998) problem of relevant details. A moderate modal sceptic, van Inwagen grants that we know many everyday modal truths like 
(TABLE) The table over there could have been two feet to the left.

But van Inwagen denies that we are in a position to know far-fetched ones. As examples of far-fetched philosophical claims he presents (van Inwagen 1998, 67-68):

(PERFECT) It is possible for there to be a perfect being (that is, a being that has all perfections essentially).

(IMMATERIAL) It is possible that I exist and nothing material exists.

(SUFFERING) It is possible that there exist vast amounts of suffering for which there is no explanation.

Van Inwagen targets modal knowledge in general. Yet his argument is entangled in several ways with conceivabilism in a broadly Yablovian version. It draws on the same general motivational sources as conceivabilism. Notwithstanding these close connections, conceivabilism provides resources for a general solution to van Inwagen's problem.

I shall proceed as follows: In section (1.1.), I introduce the problem using van Inwagen's succinct example. In (1.2.), I point out doubts that the resulting scepticism would be moderate. In (1.3.), I argue that the consequence should not be to simply dismiss either van Inwagen's argument or conceivabilism. Rather the problem is deeply entangled with plausible structural principles about metaphysical modality. In section (2.), I review two main reactions in recent literature, (2.1.) Hawke's renewal of moderate scepticism and (2.2.) Geirsson's and Hartl's antisceptical arguments. In section (3.), I present my own proposal how an 
imagination-based modal epistemology should deal with the problem. The proposal exploits Yablo's distinction between imagining a world as determinate and determinately (3.1.). The remaining issue becomes when we may simply imagine details as determinate. I show that the issue can be solved by heuristics, in particular analogical reasoning (3.2.). Discussing examples of analogical reasoning in the literature (3.2.1.), I argue that it should be integrated into the conceivability test (3.2.2.). Then I deal with limits and problems of analogical reasoning (3.2.3.-3.2.4.).

\section{The Problem of Relevant Details}

\subsection{Current Conceivabilism and the Challenge of Being Concrete}

Van Inwagen's key argument highlights the problem of relevant details. ${ }^{1}$ I quote his main example and then present my interpretation of the problem. Van Inwagen refers to Yablo's criterion that, in order to imaginatively figure out whether $p$ is possible, one has to imagine a world which one takes to verify $p$ (Yablo 1993, 29-30):

' $p$ is conceivable for me if

(CON) I can imagine a world that I take to verify $p$. '(Yablo 1993, 29)

Van Inwagen does not incur a commitment to Yablo's criterion, but his discussion seems driven by the conviction that conceiving is the salient candidate method for knowing the far-

$1 \quad$ Van Inwagen's argument has been anticipated by Tidman (1994, 304). 
fetched modal claims he is sceptical about. I shall follow him in this assumption. ${ }^{2}$ Van Inwagen presents an exemplary application of $\mathrm{CON}$ :

'A philosopher will confidently say that a (naturally) purple cow is possible, but he or she will not in fact have devoted any thought to the question whether there is a chemically possible purple pigment such that the coding for the structures that would be responsible for its production and its proper placement in a cow's coat could be coherently inserted into any DNA that was really cow DNA ... But if a philosopher has not attempted to do something like this, then that philosopher has not, in any useful sense, attempted to imagine a possible world in which there are naturally purple cows. Therefore, if Yablo's general thesis is right..., no one is even prima facie justified in believing that naturally purple cows are possible.'(van Inwagen 1998, 78)

I give my own summary of van Inwagen's point. We cannot know the truth about

(COW) There could be a naturally purple cow.

In order to imagine a world which verifies that there is a naturally purple cow, ${ }^{3}$ we would have to imagine how a natural process leads to cow DNA encoding purple pigment, specify

2 Almog $(1996,424)$ thinks that turquoise rhinos could exist because there are rhinos and it is not a condition for them to be what they are not to be turquoise. Almog approaches the question by general metaphysical considerations rather than by conceiving. I cannot discuss Almog's alternative in this paper.

3 I shall precisify the issue: a cow whose fur or skin includes a significant purple surface region as a result of natural selection. The latter requirement is problematic because 
the chemical code of purple pigment within the DNA and make plain that it is cow DNA. Since no one can imagine these scientific details, no one is in a position to know whether a naturally purple cow is possible.

One immediate concern is whether van Inwagen's argument generalizes to philosophically interesting possibility claims. I think it does. I sketch the beginning of an analogous assault on

(IMMATERIAL) It is possible that I exist and nothing material exists.

First, one may ask what the actual constitutive conditions of my being myself are. Candidates are facts about origin (my parents), constitution (my genome), being alive at some time, having a certain array of conscious experience and so on. Then one may challenge the imaginer to spell out how these features are grounded in an immaterial world.

I have suggested that van Inwagen's argument is related to the deeper motivation of Yablo's version of the conceivability criterion. Both derive their intuitive plausibility from the same general considerations on the nature of metaphysical possibility and its epistemological consequences. I shall introduce these considerations by pointing to a difference between current conceivabilism as exemplified by Yablo's criterion and (some) more traditional versions. In Yablo's criterion, we have to imagine a world. Chalmers has a similar view:

'...to positively conceive of a situation is to imagine (in some sense) a specific configuration of objects and properties. It is common to imagine situations in considerable detail, and this

cows as we know them are the product of human intervention. But we may think of natural ancestors of cows instead of cows. 
imagination is often accompanied by interpretation and reasoning.'(Chalmers 2002, 149$150){ }^{4}$

Chalmers is less committal than Yablo, but if it is 'common to imagine situations in considerable detail', doing so seems a prerequisite of justifying modal claims by imagination. A precursor of the view can already be found in Kripke:

'A possible world is given by the descriptive conditions we associate with it. What do we mean when we say "In some other possible world I would not have given this lecture today?" We just imagine the situation where I didn't decide to give this lecture or decided to give it on some other day... in theory, everything needs to be decided to make a total description of the world.'(Kripke 1980, 44, m.e. $)^{5}$

In traditional versions of conceivability, this requirement is not always to be found. Take the classical passage from Hume:

$4 \quad$ Chalmers (2002) distinguishes between primary and secondary, negative and positive conceivability. I confine myself to positive conceivability as a guide to possibility, and I shall not go into the details of semantically unstable expressions. The main difference between Yablo's and Chalmers's accounts is that, to Chalmers, ideal conceivability entails possibility, while Yablo-conceivability merely 'gestures in its direction' (Evnine 2008, 666). I think that approximating ideal conceivability poses the same challenges of being concrete as Yabloconceivability.

$5 \quad$ Kripke denies that one can provide such a description, though (cf. section 3.1.1.). 
'Tis an establish'd maxim in metaphysics, That whatever the mind clearly conceives includes the idea of possible existence, or in other words, that nothing we imagine is absolutely impossible. We can form the idea of a golden mountain, and from thence conclude that such a mountain may actually exist. We can form no idea of a mountain without a valley, and therefore regard it as impossible.'(Hume 1739-40, 1.2.2.8, 32)

One may wonder whether current practice of using conceivability evidence really abides by the requirement of imagining a world. Still it is striking to see expert conceivabilists endorse this requirement. There is an obvious connection to van Inwagen's scepticism. His cow example is driven by the requirement of embedding the representation of a naturally purple cow into something more concrete, perhaps not a world, but at least into some much more determinate scenario.

These observations give rise to the suspicion that van Inwagen's scepticism only arises because current epistemologists misunderstood the conceivability criterion. Perhaps it arises from exaggerated demands imposed on conceivability. This suspicion is further nourished by an argument that van Inwagen's scepticism cannot be moderate.

\subsection{The Spectre of Pervasive Modal Scepticism}

Van Inwagen takes his sceptical argument to show that we cannot know far-fetched modal claims. Still he is confident that we know many mundane modal claims like TABLE, although he confesses that he cannot tell how we acquire such mundane modal knowledge. While van Inwagen is only moderately sceptical, I shall explore motives for a more general modal scepticism. 
One easy response to van Inwagen is the following: if it is a legitimate move to insist that we know mundane modal claims without telling how, why can't we apply this move to farfetched modal claims? Why do we have to use Yablo's criterion and then get enmeshed in the sceptical problem? One way of evading this response is to insist that Yablo's criterion has to be applied across the board. I have quoted Yablo's claim that philosophers have not discovered a serious alternative to conceivability as a pathway to modal knowledge. Assume for a moment that there is no alternative. Then the spectre of pervasive modal scepticism arises. Heimir Geirsson has pointed out that van Inwagen's argument also applies in cases like TABLE. We may be challenged to represent in detail the full molecular structure of some reality where the table is placed two feet to the left, at least in the small region that will clearly be different from actuality. We cannot do that, and hence we cannot know TABLE, or so it seems.

Geirsson's own examples are the following:

(RECORD) There could be a record-player which is completely free of background noises. (KENNEDY) Kennedy could have died from natural causes.

To Geirsson, we can know RECORD and KENNEDY. However, just as in the case of COW, in order to know that there could be a noise-free record-player,

'one would have to imagine the details of the technology that allows one to play records without background noise, and it is implausible to assume that anyone can do so.'(Geirsson 2005, 287)

Imagining the Kennedy scenario 
'... involves, for example, imagining how the course of U.S. history, and world history, might have been had Kennedy not been shot. In addition to that, it would involve imagining some detail about the lives of those close to Kennedy... Might Jackie have married Onassis, and if so, what might the wedding ceremony have been like?'(Geirsson 2005, 288)

Geirsson uses his examples to argue that the standards employed by van Inwagen are excessive. Thus Geirsson rejects the requirement to specify the DNA of a naturally purple cow as overdemanding.

On the one hand, pervasive modal scepticism clearly is unattractive. On the other hand, I report a differentiated set of intuitions. I am adamant that TABLE is true. As for KENNEDY, I also tend to dismiss a request for details about world history or Jackie and Onassis. As for RECORD, I feel mildly puzzled about the technical details. As for COW, van Inwagen's insistence on specifying cow DNA really makes me uncertain.

I shall try to account for these differentiated intuitions. My general suggestion is that they testify to the relevance of being concrete, as captured by Yablo's criterion, but that the requirement of being concrete has to be qualified. However, in the next section I shall first consider a general motivation of the criterion by our understanding of metaphysical modality.

\subsection{Why To Be Concrete}

I introduce my motivational consideration by the following metaphysical question: what is it for some $p$ to be metaphysically possible? While a general account of metaphysical modality is far beyond my scope, one independently plausible structural requirement looms in the background of Yablo's criterion. It is captured by the following claim: 
'Maximally specific ways the world could have been are commonly called 'possible worlds.' The apparatus of possible worlds allows us to introduce a set of modal notions: a proposition is necessary just in case it is true in all possible worlds, a proposition is possible just in case it is true in some possible worlds, and it is contingent just in case it is true in some but not all possible worlds.'(Kment 2012)

From this quote, we can derive the following structural requirement:

(DETERMINACY) $p$ is possible iff it is true at a possible world. ${ }^{6}$

There are several uncertainties about DETERMINACY, which I can only mention without thoroughly discussing them.

Firstly, is DETERMINACY really a matter of course? Modalists like Bueno and Shalkowski, who generally reject the possible worlds-framework and think that modality is primitive, would reject DETERMINACY. However, they are also sceptical about more demanding philosophical possibility claims (Bueno and Shalkowski 2015, 671). ${ }^{7}$ There are concerns that such claims become unintelligible if metaphysical modality is primitive. Since they are the main rationale for coming up with the notion of metaphysical possibility in the first place, the modalist position may lead to questioning the very usefulness of this notion.

Secondly, in CON, Yablo only talks of imagining a world. Yablo adds that a world has to be 'complete in every respect: spatially, temporally, and ontologically, for instance'(Yablo 1993,

6 In Kment (2014, ch. 4-5), worlds are classes of Russellian propositions which describe reality in maximal detail. Worlds do not have to be metaphysically possible. 7 Moreover, there are doubts whether Bueno and Shalkowski really have in mind the same kind of modality as Yablo, van Inwagen \&co (cf. Bueno and Shalkowski 2015, 679). 
29). However, it has been argued that completeness is not sufficient for a world to be possible (Fiocco 2007, 369). A plausible requirement is that no contradiction should be true of a possible world. I shall make do with this requirement, but further conditions may have to be added.

I have introduced DETERMINACY as a structural requirement for metaphysical possibility. I shall now draw an epistemological lesson. DETERMINACY sets a standard for justifying claims to possibility. Judging from DETERMINACY, in claiming $p$ to be possible, one commits oneself to the possibility of a world verifying $p$. The rationale of conceivabilism is that one represents what one claims to be possible. If conceivability is to provide evidence for a world being possible, one has to represent that world.

Reflections of this requirement can be found especially in the quotes from Yablo, Chalmers and Kripke from section (1.1.). I shall formulate a Yablovian condition of justification:

(CONCRETION) One is justified to believe that $p$ is possible if one entertains a suitably concrete and consistent representation of a world which one takes to verify $p$.

One major aim of Yablo is to account for modal error. ${ }^{8}$ In how far does my proposal live up to that aim? My proposal is reconcilable with several explanations of modal error. CONCRETION figures in some of them.

The main source of error I am interested in is that one fails to satisfy CONCRETION because one's representation of a world is not sufficiently concrete. Other sources of error can be reconciled with satisfying CONCRETION. Consider Kripke's strategy of explaining conceivability-based modal error: one takes the imagined scenario to verify $p$, but in fact the imagined scenario only verifies $p^{\prime}$. The plausibility of the strategy depends on how easy it is

\footnotetext{
${ }^{8}$ Thanks to an anonymous reviewer for reminding me of this.
} 
to confuse scenarios which verify $p$ with scenarios which verify $p^{\prime}$. To give an example: assume material constitution is necessary. Mary knows that the table in front of her is made of wood. However, she convinces herself that it could be made of ice by imagining a qualitative facsimile of her situation in which the table in front of her is made of ice (cf. Kripke 1980, 114). Her error can be explained as follows: she confuses her consistent and suitably concrete imagination of a situation in which she has a duplicate table in front of her and the imagination of a situation in which this table (actually in front of her) is made of ice. ${ }^{9}$

In other cases, modal error may be traceable to ignorance of facts: assume George, who does not know that Hesperus is Phosphorus, entertains a consistent and sufficiently detailed representation of a world in which the heavenly body visible in the evening is different from the heavenly body visible in the morning. In taking this world to be a world in which Hesperus is different from Phosphorus, George becomes justified in his false belief that Hesperus could be different from Phosphorus. But for a world to verify that Hesperus was not Phosphorus, it would have to be a world in which Hesperus was different from itself. And there can be no suitably detailed and consistent representation of such a world. In this case, ignorance of the fact that Hesperus is Phosphorus plays a key role in explaining modal error. In sum, CONCRETION is compatible with several patterns of explaining modal error.

Whenever one comes up with a claim to possibility, one may be challenged to tell why one does not have to specify a certain relevant detail to satisfy CONCRETION. Van Inwagen's argument can be seen as an application of this general scheme. Surely a naturally purple cow

\footnotetext{
${ }^{9}$ Yablo (2006) argues that the standards for a facsimile situation are high. The situation must be indistinguishable from the original for Mary with her sensibilities undisturbed under standard circumstances of their use. He doubts that Kripke's strategy works for examples like 'heat could be low instead of high mean molecular motion'.
} 
must have a determinate DNA to form part of a concrete reality. If one endorses COW, one may be challenged to tell why one does not have to specify the DNA.

I have confined my attention to conceivabilism. While I do not claim that van Inwagen's problem arises for any positive modal epistemology, it tends to spread. Take Williamson's (2007) counterfactual-based theory: First one supposes $p$ to be true, and then the counterfactual supposition is imaginatively developed in order to see whether a contradiction ensues. In order to test whether $\mathrm{COW}$, we have to develop the counterfactual supposition that there is a naturally purple cow. But when does a development count as sufficient? Against Williamson, van Inwagen may insist that one has to elaborate what genome a naturally purple cow would (or at least might) have.

Summarizing: on the one hand, CONCRETION seems well-motivated as a principle behind current versions of conceivabilism. On the other hand, it raises the spectre of pervasive modal scepticism. Before providing my own answer to the sceptical threat, I shall critically review extant reactions in the literature.

\section{Extant Reactions in the Literature}

\subsection{A Moderately Sceptical Reaction}

Peter Hawke (2011) has given van Inwagen's sceptical argument a new twist. He presents the following tight conditions for an imagined scenario to provide evidence that $p$ is possible: $p$ has to be logically entailed by a set of other propositions $p 1, \ldots p n$, which are all true in the imagined scenario. Each of these propositions has to be 'less modally controversial' than $p$ (Hawke 2011, 359). Details matter as far as the imagined scenario has to be sufficiently rich to entail $p$. Hawke agrees with van Inwagen that some everyday modal claims satisfy this condition, but far-fetched philosophical possibility claims do not. 
Here is the rub: Hawke demands that any single member of the relevant set $p 1, \ldots p n$ be 'less modally controversial' than $p$. Although this sounds like a strong requirement, it is clearly too weak. Each proposition in the set may be non-controversially possible, taken individually, but nothing follows for their conjunction. Instead of the individual conjuncts taken separately, we would have to establish the conjunction as non-controversial first. However, since the conjunction is to entail $p$, it can be expected to be at least as controversial as $p$ itself. We might find the conjunction non-controversial as long as we do not attend to $p$. But as soon as we infer $p$, the conjunction should become controversial. Hence I do not see how we might use it to establish the possibility of $p$.

One source of the problem lies in Hawke's insistence that $p$ must be entailed by the scenario without being stipulated. I distinguish two ways for $p$ to be modally imagined/conceived. The first way is that some scenario spontaneously strikes us as a scenario verifying $p$. This does not always require an entailment relation. For instance, a Gettier scenario may be found modally uncontroversial and at the same time spontaneously strike us as verifying that the protagonist has justified true belief without knowledge (NKJTB). A scenario like this may convince us that a case of $N K J T B$ is possible. However, a normal Gettier description does not entail that the subject has NKJTB (cf. Williamson 2007, 285).

The second way for $p$ to be imagined is by stipulation. ${ }^{10}$ Pace Hawke, when we use imagination to figure out whether $p$ is possible, we will often stipulate that $p$ and then add certain relevant details in order to test whether there is a way for $p$ to be part of a concrete

10 My distinction is similar to Kung's (2016) distinction of imagistic and assigned content. To Kung, assigned content either is simply stipulated or comes as a spontaneous 'label'. For instance, an image popping up in your head may spontaneously be taken to show your grandmother. Yet I do not think that labelling covers all ways in which a scenario can be spontaneously taken for a scenario that verifies $p$. 
reality. To illustrate the role of stipulations in the literature, I point to Kripke's $(1980,44)$ claim that possible scenarios are stipulated. Not everything may be freely stipulated for imagination to provide modal knowledge. But rather than $p$, the proposition to be tested for its possibility, the limits of stipulation concern ways for $p$ to be concrete. In order to find out whether COW, we may stipulate that there be a naturally purple cow, and we may fill in certain details by stipulation, but we may not stipulate that the cow does not have DNA. Proper conceiving must be constrained by an awareness of such limitations. Again I draw an analogy between the conceivability test and Williamson's (2007) counterfactual-based theory. The role of a counterfactual supposition is relevantly similar to the role of stipulation in modal imagination. Hawke's ban on stipulation is unmotivated.

I close with an important insight of Hawke's, which I shall build on. According to Hawke, the individual propositions $p 1, \ldots p n$ forming the conjunction which is to entail the modally controversial $p$ are established as modally uncontroversial by their relevant similarity to actual facts. However, the role of similarity is highly restricted (Hawke 2011, 361). As I shall argue, similarity to modally uncontroversial features of reality plays a broader role in heuristic techniques of making $p$-scenarios concrete.

\subsection{Antisceptical Reactions}

I shall now turn to authors who reject van Inwagen's scepticism, in particular Geirsson (2005) and Hartl (2016). Geirsson rejects CONCRETION, pointing out that van Inwagen's scepticism tends to spread (cf. 1.2.). Geirsson's view is that any imagining that $p$ provides some justification for believing $p$ to be possible. Justification gradually increases with filling in relevant details, but it remains defeasible by evidence which either directly undermines it or independently supports the necessity of not- $p$. 
My doubts concern the part about imagination. As sceptics about the comprehensive role of Yablovian imagination have pointed out, imagination is not always constrained by metaphysical modality (e.g. Tidman 1994, Byrne 2007, Fiocco 2007, Kung 2010, 2016):

'I imagine myself receiving the Fields medal for proving Goldbach's conjecture. ... I imagine (and I suggest that you have imagined too) that I really have proved it. I can also engage in a similar imaginative project: I can imagine disproving Goldbach's conjecture.'(cf. Kung 2016, 96).

We can imagine the falsity of Goldbach's Conjecture, for instance in a piece of fiction. But we do not thereby get evidence that Goldbach's Conjecture could be false.

One may reply that there is a salient defeater whenever the function of imagination is not properly constrained, but the reply would misconstrue the point: sometimes imagining that $p$ provides no justification to begin with, not even defeasible justification. Pace Geirsson, there are exercises of imagining that $p$ which do not provide any justification that $p$ is possible. They are not in the business of doing so: '...there are kinds of conceivability that do not portray $p$ as possible...'(Yablo 1993, 5)

Sceptics about modal imagination tend to neglect that imagination serves many purposes; it can be subject to many constraints and success conditions (cf. Kind 2016). But it will not do to simply say that imagination that $p$ provides justification that $p$ is possible unless there is a salient defeater. A more convincing starting point for confining a properly constrained role of imagining or conceiving is the requirement of accurately representing a world one takes to verify $p$ as captured in CONCRETION.

I shall close this section with some remarks about Hartl's (2016) variant of the view: 
'Rather than looking for precise criteria about the extent to which a possible world must be conceived, we need to rely on a more detailed and coherent view of how defeaters work in the modal context... in absence of proper defeaters Yablo-style conceivability does justify the belief that the conceived scenario is possible. The burden of proof is always on sceptic's side: to reject a given possibility claim, the sceptic should find a defeater for that particular possibility claim.'(Hartl 2016, 280)

The problem with this passage is what 'Yablo-style conceivability' is supposed to be. The key condition that defines Yablo-conceivability is CON: imagine a world you take to verify that $p$. I grant that, once we Yablo-imagine that $p$, defeaters may roughly play the role envisaged by Geirsson and Hartl. But van Inwagen does not target justification already provided by Yabloconceiving. He raises doubts that a naturally purple cow is Yablo-conceivable in the first place, and here the burden of proof is on the side of the imaginer. Hartl provides no answer how we are supposed to meet Yablo's requirement of imagining a world that we take to verify $p$, nor does he come up with a convincing candidate for a weaker condition of modal justification than CON. My task in the next section is to explain how we can meet the conditions of Yablo-conceivability.

Besides Yablo-conceivability, Hartl offers analogical reasoning as an alternative pathway to modal knowledge. I shall argue for integrating analogical reasoning into the conceivability test. In any case, this agreement between moderate sceptics and their opponents on the relevance of similarity-based reasoning is evidence that the latter will play a key role in a convincing reply to van Inwagen.

\section{My Proposal}

\section{1. 'As Determinate' vs. 'Determinately'}


I shall now develop my positive proposal. Starting from CONCRETION, I shall present ways of being concrete. The straightforward way of being concrete is to specify details. This leads to the idea of a complete, fully detailed representation of a world. However, it is not a matter of course that there is anything like such a complete representation, and it would be unattainable for a finite mind anyway.

The problem can already be found in the passage from Kripke referred to in section (1.1.). Kripke continues:

'... Of course, we don't imagine everything that is true or false, but only those things relevant to my giving the lecture; but, in theory, everything needs to be decided to make a total description of the world. We can't really imagine that except in part; that, then, is a "possible world".'(Kripke 1980, 44)

Kripke's remark is puzzling. He might be understood as saying that a possible world is only part of a determinate reality. But then of course the question becomes how to deal with his admitting that, 'in theory, everything needs to be decided'. The considerations to come are my proposal how to deal with this puzzle.

Perhaps the most important clue is Yablo's distinction between imagining a world determinately and merely imagining a world as determinate. One may imagine a tiger and count each of the tiger's stripes, and one may merely imagine a tiger with a determinate number of stripes without specifying how many stripes it has (Yablo 1993, 37). Imagining a world as determinate in respect $\mathrm{R}$ (the number of stripes) sometimes allows to discharge the requirement of being concrete about $\mathrm{R}$ (counting stripes). Often we feel that some parts of a world simply do not bear on whether $p$. When I consider TABLE, what happens outside a range of several square meters seems irrelevant. As for KENNEDY, if someone were to ask for American history up to Kennedy's birth or Jackie's relationship to Onassis after 
Kennedy's natural death, we would dismiss such questions as beside the point. We may imagine irrelevant parts of the world as determinate.

However, Yablo's distinction so far is underdeveloped. The criterion of imaginability would be trivialized if we could simply disregard any neuralgic detail as determinate. Yablo does not tell when the 'as determinate'-clause may be invoked in a non-trivializing way. Even the irrelevance presumptions of common sense are not a matter of course: to Spinoza and Leibniz, everything is metaphysically entangled. The question is how to account for these presumptions. I shall elaborate one exemplary heuristic tool that provides guidance when we may simply imagine details as determinate but not determinately.

The heuristics to be considered are not an ad hoc fix. Whenever we dwell on hypothetical scenarios, be it in judging issues of possibility, in thought experimental reasoning, in reading novels, cooking recipes or whatever, we often feel the need to settle certain details beyond the explicit description we are given and leave other details unspecified (cf. Jackson 2011, 478). Even a sceptic about modal knowledge is faced with the question of how to account for this general practice. There may well be different mechanisms involved for different kinds of scenarios, but it would be arbitrary to insist that there are such mechanisms for thought experiments and fictions but not for modal imagination. In the following, I develop one salient mechanism.

\subsection{The Modal Role of Analogical Reasoning}

\subsubsection{Extant Research}

My candidate for the heuristic at stake is analogical reasoning. I am open to the idea that there are other mechanisms involved. I start with a motivational consideration: analogical reasoning is widely accepted to play a key role in a field closely related to modal epistemology: the semantics of counterfactuals. Though intensely debated, the Lewisian (1986) paradigm of 
accounting for the semantics of counterfactuals in terms of overall similarity of worlds remains by far the most prominent approach, at least in philosophy. I do not commit myself to a similarity approach to counterfactuals, but if it works, it supports using analogical reasoning in modal epistemology more generally (cf. Kment 2014).

The salience of analogical reasoning as a means of solving van Inwagen's problem is confirmed by the literature. We have seen that both Hawke and Hartl give analogical reasoning a role in dealing with van Inwagen's challenge. In order to further support my proposal, I shall briefly review a recent account exclusively based on similarity, which also bears on COW. Sonia Roca-Royes (2017) aims at accounting for everyday reasoning about de re possibilities like: John is bald. Hence Jack could also be bald. More generally, Roca-Royes proposes to account for the de re-possibility that $b$ could be $G$ by the following schema:

$a$ is actually $F$ and $G$.

$b$ is actually $F$.

Hence, $b$ could also be $G$.

$a, b$ are individual constants, $F$ and $G$ are features like being human, being bald. $F$ is an intrinsic feature of $a, b$. For instance, John and Jack are human. John is bald. Hence, Jack could also be bald. In classifying $a$ and (potentially) $b$ together under $G$, one uses mechanisms of 'amplifying' knowledge of actual facts, in particular induction and abduction. One is guided by the following maxims:

(a) There is a 'nomic' relationship between on the one hand intrinsic features and on the other hand causal role.

(b) Nature is uniform. 
(c) The fewer actual cases of $F$-cum- $G$ one encounters, the more determinate the common intrinsic features $F$ have to be to support modal analogies involving $G$.

Applied to my example, since John's intrinsic features support his being bald, the intrinsic features shared by John and Jack could also support Jack being bald.

I think that Roca-Royes's account has to be integrated into a broader approach:

Limiting the use of analogical reasoning to actual things as Roca-Royes does leads to implausible limitations on considering possibilia. ${ }^{11}$ This has strange consequences: for instance, Roca-Royes takes her method to provide knowledge that Gandhi could have been born one day earlier, two days earlier..., as long as embryo Gandhi already existed, but not that he could have been born one year earlier (Roca-Royes 2017, 235). Presumably our confidence that Gandhi could have been born at a different date decreases the farther the date is from his actual date of birth, but I doubt that it makes all the difference whether embryo Gandhi already existed at the time or not. Roca-Royes's method needs to be embedded into other methods of modal reasoning to account for intuitions in the Gandhi case. ${ }^{12}$

There are further reasons to go beyond actually existing individuals. To estimate how farfetched the scenario of a naturally purple cow is, Roca-Royes considers whether some actual cows (which are not purple, of course) could have been purple (Roca-Royes 2017, 235). I doubt that this detour is the right way of measuring modal remoteness. When dwelling on COW, we should be open to imagining an alternate evolutionary history, which issues in different individuals. The cows conceived are possibilia. These concerns about Roca-Royes's

\footnotetext{
${ }^{11}$ I intend to be neutral on the necessitism-contingentism debate.

${ }^{12}$ I only assume that the sharp cut is unintuitive as long as we are not given further arguments which go beyond Roca-Royes's method. Such arguments can be found in (Almog 1996, 416).
} 
account further motivate a broader approach to analogical reasoning on modal issues, one that includes imagining possibilia.

My brief discussion of Roca-Royes's account motivates a broader approach: a heuristic as outlined by Roca-Royes is compatible with conceivability forming the ultimate unified criterion of metaphysical possibility. Let our reasoning from $a$ being $F$ and $G$ to $b$ being $F$ and possibly $G$ proceed via imagining $b$ being $F$ and $G$. Uncertainties about the details of $b$ being $G$ are overcome by imagining the circumstances of $b$ as determinate in largely the same way as in the case of $a$. In this exercise of imagination, analogical reasoning works in a holistic way instead of being limited to Roca-Royes principles (a)-(c). As we shall see, the intuitions about Gandhi's birth can be accounted for. Moreover, imagining worlds inhabited by different individuals than the actual one is a promising way of addressing possibilia.

There are further examples of a modal use of analogical reasoning which are best understood within a conceivability approach. Hartl (2016, section 5 and 6) discusses Putnam's super(super-)spartans who never show pain behaviour (cf. Putnam 1980, 29-30) and a world without suffering. He suggests the following procedure: we start from cases where some feature is instantiated and then step-by-step generalize the instantiation of this feature. Concerning super-spartans, we start from actual fakirs and fire-walkers and then proceed to people who never display pain behaviour. In considering a world without suffering, we start from actual cases of people who do not suffer and then step-by-step exterminate any suffering.

Hartl admits that Putnam himself used conceivability evidence in motivating his example. Indeed there are good reasons to embed Hartl's use of analogical reasoning into conceivabilism. It is not clear what the intermediate steps in generalizing the pertinent features are supposed to represent. One attractive proposal is to interpret them as pieces of imagination. One does not simply generalize suppressing pain behaviour or lack of suffering to whole lives and populations. Rather one imagines a series of scenarios connected by overall 
similarity, starting with modally perfectly uncontroversial ones, until one reaches the intended one. From some point onwards, one will have to imagine merely possible scenarios. In a similar vein, we may start with imagining Gandhi having been born 1, 2, 3 months earlier and proceed to his having been born 9 months earlier, 9 months and a day earlier... The process is best understood as involving a series of imagined scenarios $1, \ldots m \ldots n$, starting from actuality, which are related as follows: scenario $m$ seems possible because it may be imagined as mutatis mutandis- determinate in the same way as scenario $m$-1, which is already accepted as possible. ${ }^{13}$ It seems plausible that one's rational confidence tends to decrease the farther one gets from the uncontroversial scenarios one started with.

I shall add a further example, which even better illustrates why to integrate analogical reasoning into conceivability. Uriah Kriegel (2015) imagines a sensory-algedonic-emotional zombie in order to argue for the possibility of purely cognitive phenomenology: he starts with imagining different subjects who have higher cognitive states but (a) who are neither capable of vision nor visualization, (b) the same for any senses, (c) the same for feelings, (d) emotions. Then he combines (a)-(d) in one person. As a final step, he imagines what it is like for that person to be in a cognitive state.

Kriegel's argument has been thoroughly questioned (Chudnoff 2015, ch. 3). I present it not as an example of successful imagination, but as a typical (and methodologically unproblematic) case where analogical reasoning is combined with an extra effort of imagination. The procedure of combining (a)-(d) closely resembles Hartl's procedure. One starts from modally uncontroversial cases (a), (b)... and combines them successively until reaching a case which normally would seem controversial. The part about the phenomenology experienced by the

13 A further principle that can be integrated in this way into conceivabilism is Rasmussen's (2014) principle of continuity: roughly, a scenario which differs from a possible scenario only in degree is likewise possible. 
zombie is no piece of analogical reasoning. One imagines the zombie combining (a)-(d) and then imaginatively puts oneself into the shoes of the zombie to see whether the zombie enjoys cognitive phenomenology. The disagreement between Kriegel and his detractors begins at that point: do we have to conceive the zombie as enjoying phenomenology or not (see my section 3.2.3.)? Integrating the modal use of analogical reasoning into conceivabilism allows me to account for a philosophical practice like Kriegel's.

In sum, conceivabilism lends itself to systematically integrating variegated tendencies in the literature to give analogical reasoning a role in modal epistemology.

\subsubsection{Dual Approach: Analogical Reasoning in the Conceivability Test}

In this section, I shall present a unified proposal how analogical reasoning can be used to imagine scenarios as determinate. I use the examples and paradigmatic accounts discussed so far to elaborate the proposal.

We have seen that several authors invoke analogical reasoning in their reaction to van Inwagen's challenge. Felipe Leon even suggests that we might settle COW by using analogical reasoning $(2017,257)$. I shall consider an exemplary assault on COW along these lines. We need modally uncontroversial precedents for the details we cannot specify. Search will be guided by identifying relevant resemblance classes. Thinking about COW, we look for naturally purple animals which are maximally close to cows in the most natural taxonomy. With a little googling, I came upon mandrills, a kind of primate whose skin shows bright colours from red to blue. Mandrills might be the natural precedent for naturally purple cows. I do not claim that the analogy allows a definite verdict on COW, but it ceteris paribus has a positive impact on one's rational credence in COW.

To illustrate this positive impact, I consider the role of analogical reasoning in acquiring beliefs about the actual world. Your beliefs about cows are partly due to your considering 
cows as instances of different resemblance classes. Mammals are an outstanding resemblance class for cows due to their overall role in biological theorizing. This role is not affected by our ignorance about cow DNA. Assume you do not know about mandrills. Your initial rational credence in there being naturally purple cows $\mathrm{C}_{0}$ (there are purple cows) will be very low albeit not zero; you might get empirical evidence that there are naturally purple cows, which would raise your credence. Part of this evidence may be information about mandrills, which presumably has a minuscule positive impact on your credence $\left(\mathrm{C}_{0}\right.$ (there are purple cows $)<\mathrm{C}_{0}$ (there are purple cows|there are mandrills, i.e. purple mammals)): if there are purple primates, there might be purple cows. This parallel to the role of analogical reasoning in forming non-modal beliefs supports that analogical reasoning may play a role in establishing possibility. Just as information about mandrills minimally raises your credence that there are naturally purple cows, it may raise your credence that there could be.

However, the parallel is limited. To settle COW, we do not have to consider first whether there actually are purple cows. We do not even have to consider first whether the actual cows could be purple. The modal use of analogical reasoning is not limited to actual things. And the evidential basis is broader than encoded in Roca-Royes's maxims (a)-(c); it includes any theoretical relationships between the items compared. In assessing the analogy to mandrills, we rely on everything we know about cows and mandrills. Mammals as a resemblance class are supported by biology as a whole, especially general knowledge about taxonomy, genetic make-up, and evolutionary theory. Guided by the analogy, we try to imagine an alternative evolutionary history where purple genes slipped into cow DNA as they definitely have slipped into mandrill DNA. The analogy to mandrills provides a precedent. If we judge the evolutionary histories of mandrills and purple cows to be sufficiently similar, we are inclined to accept that purple cows could have evolved like mandrills. We consider the minutes of our imagined evolutionary history as determinate in the same way as the actual evolution of mandrills. 
Having discussed COW, I shall also consider the cases which gave rise to a differentiated set of intuitions in (1.2.), beginning with the unproblematic ones. As for TABLE, any experiences with actually moving medium-sized dry goods may be used to draw analogies. In a great many of these experiences, moving was unproblematic as long as there was sufficient space. The molecular deep structure did not interfere. Hence we may regard the latter as determinate in imagining moving the table. The table may be imagined as being moved in the same way as other tables before.

Considering KENNEDY, the overwhelmingly many people who died from natural causes, especially in the US at the time of Kennedy, provide a solid base for drawing analogies to a scenario where Kennedy died from natural causes. In contrast, Kennedy's non-natural death seems to accidentally interfere with the normal course of things. Kennedy may be imagined to have died in the same way as most of his contemporaries.

RECORD illustrates how analogical reasoning may be integrated into an exacting imaginative endeavour. It is natural to start with analogies: there is a good scientific understanding of sound waves, and there are well-developed techniques of their manipulation. These techniques allow to single out and smoothen disturbing sound waves. We may imagine an advanced technique like that. Still there is the issue of integrating the device into a record player. For instance, imagine an old-fashioned record-player enclosed in a soundproof bubble. The advanced technology allows to detect and perfectly smoothen out just the noise while letting the music pass. The technical details are imagined as determinate by analogy, but the whole device is the result of a genuine piece of combinatorial imagination.

Taking stock, analogical reasoning seems to play a pervasive role in reasoning from actual to non-actual scenarios. Extant proposals only cover a small and somewhat arbitrary part of this role. In particular, they do not cover the integration of analogical reasoning into an exercise of imagination. Conceivabilism provides a sufficiently broad and flexible framework for the modal role of analogical reasoning. I start from CONCRETION. 
(CONCRETION) One is justified to believe that $p$ is possible if one entertains a suitably concrete and consistent representation of a world which one takes to verify $p$.

Now I add: a representation of a world is suitably concrete and consistent precisely if firstly, the explicit representation of details is consistent; secondly, any detail that is not explicitly imagined can be regarded as determinate. ${ }^{14}$ Any detail that is not explicitly imagined can be regarded as determinate precisely if some $p$-world as imagined seems sufficiently similar to the actual world. The background assumption is that impossible worlds do not seem sufficiently similar to the actual one.

Objection: why not the other way round? Instead of integrating analogical reasoning into CONCRETION, we may simply ask whether some $p$-world as imagined is sufficiently similar to the actual world. In reply, when philosophers like Putnam want to justify a claim that $p$ is possible (super-spartans are possible), they argue that they can conceive a $p$-world and not that some $p$-world is sufficiently similar to the actual one. This is evidence that similarity comes into play only as an auxiliary heuristic tool. It allows you to settle when your conceiving is sufficiently developed. But it is only a makeshift. In the next section, I shall point out its shortcomings. If we had unlimited cognitive resources, it would be preferable to further elaborate our imagination of a $p$-world.

In sum, I propose to integrate analogical reasoning into the conceivability test. We have to specify our imagination of a $p$-world until we feel that the rest can be regarded as determinate as it seems sufficiently similar to the actual world. One motive for this integrative effort is unification. More specifically, we get a plausible dual approach to questions of possibility. Everyday possibilities seem unproblematic because we can imagine almost anything as

\footnotetext{
14 'Explicit' here includes pictorial representation.
} 
determinate in the same way as in the actual world. The effort of conceiving a scenario goes almost unnoticed as the 'as determinate'-clause is invoked largely automatically. In contrast, more problematic possibilities as exemplified by RECORD and COW or Kriegel's zombie scenario often require an effort which goes beyond analogical reasoning. One may still consider almost anything as determinate, but certain details will need special elaboration.

\subsubsection{Limits of Analogical Reasoning}

In the last section, I have illustrated the modal role of analogical reasoning as a shortcut to satisfying CONCRETION. In this section, I shall inquire into the limits of analogical reasoning. My result will be that analogical reasoning is highly problematic, but given its ubiquity, there is no reason for modal scepticism in particular.

I shall use the explicit targets of van Inwagen's scepticism to highlight two exacting requirements of using analogical reasoning. The first requirement is that one comparandum is actuality. Consider:

(PERFECT) It is possible for there to be a perfect being (that is, a being that has all perfections essentially).

(IMMATERIAL) It is possible that I exist and nothing material exists.

In both cases the availability of a shortcut depends on one's take on actuality. If one already believes in metaphysical perfection, or if one believes in unembodied mental properties, one might well find perfect beings and oneself unembodied sufficiently close to actuality. Otherwise one might be deterred by relevant disanalogies: perfections and immaterial thinking subjects instantiate 'alien' properties, which make for highly relevant dissimilarities (cf. Lewis 1994, 474-475). In a similar vein, I surmise that the disagreement on the sensory- 
emotional-algedonic zombie may be due to background beliefs on whether there is cognitive phenomenology. Disagreement on many philosophically relevant possibility claims arises from differences in non-modal background beliefs, which delimit the range of potential analogies to be drawn.

The second problematic requirement codified by ANALOGY can be illustrated by the analogy between cows and mandrills: in order to satisfy CONCRETION with regard to the problematic $p$ (there are naturally purple cows), the complete unspecified details about some world verifying $p$ have to be settled in a way relevantly similar to actuality. Drawing an analogy to mandrills contributes to finding a world with naturally purple cows sufficiently similar to the actual one. The analogy involves a difficult intuitive trade-off, which rests on the whole of biological knowledge, but which one may not be able to fully explicate. Mandrills are a better precedent for naturally purple cows than purple butterflies, chameleons, or even birds. But are they good enough? Where are we to draw the line between a precedent which is sufficiently close and one that is not? 'Sufficiently similar' has to be interpreted as the result of such a trade-off. The difficulty of the trade-off in assessing COW explains why we find the case more problematic than TABLE, KENNEDY, and RECORD.

The difficult trade-off in the cow-mandrill analogy adds to general concerns in the literature that similarities and dissimilarities are often incommensurable. To use Keynes's beautiful example, is a book bound in red morocco overall more similar to a book bound in blue morocco or to a book bound in red calf (cf. Keynes 1921, 119, Morreau 2010)? Besides such principled concerns, there is ample psychological evidence both for the pervasive use and the frequent abuse of analogical reasoning. For instance, when subjects are told two similar stories one after the other, they tend to automatically draw analogies and erroneously remember corresponding claims as having been explicitly stated (Day and Gentner 2007). It has been argued that such fallacies and biases of analogical reasoning give rise to philosophical misconceptions (cf. Fischer 2014). 
The problems mentioned may lead to sceptical worries about the modal use of analogical reasoning. In the final section, I shall argue that they do not motivate a specific modal scepticism.

\subsubsection{Modal Scepticism about Analogical Reasoning?}

As witnessed by the psychological evidence, analogical reasoning is so pervasive in everyday life that we arguably cannot do without it. Its largely automatic functioning is calibrated by experience and theorizing about the actual world. It may be tempered by reflective criticism. Everyday heuristic use of analogical reasoning provides a case for heuristically using it also in modal considerations.

Against this a modal sceptic may object that modal knowledge is special. We might be especially bad at assessing analogies and disanalogies in the case of far-fetched scenarios. When arguing for moderate modal scepticism, van Inwagen draws a comparison to unaided perception, which is only reliable at close range. He points to our inability to judge the absolute sizes of sun and moon just by looking at them (van Inwagen 1998, 70). Similar doubts may apply to analogical reasoning about far-fetched scenarios.

The argument can be turned against the sceptic. No one would take herself to be in a position to judge the sizes of sun and moon by looking at them. This restraint may be explained as follows: in making perception-based judgements, we rely on our in-built monitoring of our perceptual situation: is it favourable enough for settling an issue? When we look at sun and moon, implicit monitoring prevents us from making precocious judgements about their size. The confidence we place in our judgement normally is sensitive to this assessment. When making a confident perception-based judgement, we can defeasibly be expected to be sufficiently well-placed to make this judgement; otherwise we would not feel confidence. 
In a similar vein, on pain of pervasive scepticism, whenever we confidently rely on analogical reasoning, we can defeasibly be expected to be sufficiently well-placed to assess relevant similarities and dissimilarities. Confident similarity judgements are often biased, as witnessed by the psychological experiments. But biases are negligible weighed against a largely successful and indispensable epistemic practice.

If the moderate sceptic nevertheless insists that the confidence placed in judgements of similarity may be trusted in judgements about factual but not in judgements about modal issues, she has to face two problems:

Firstly, she has to give reasons why the modal case is special. The reason cannot be that our confidence is likely to go astray in situations where judgements of similarity are not reliable, because then the same should go for judgements of actual similarities. We could not use our confident judgement to tell apart situations where we may and situations where we may not rely on analogical reasoning.

Secondly, again the moderate sceptic would be faced with the spectre of pervasive modal scepticism. We have seen that the problem of details arises for everyday and far-fetched modal claims alike. How is the sceptic to tell them apart? The straightforward answer is that she has to judge the far-fetched cases to be relevantly dissimilar to actuality. But in order to do so, she has to rely on her confident assessment of similarity.

In sum, the heuristic use of analogical reasoning, though highly problematic, does not give rise to moderate modal scepticism. We normally can rely on confident judgements of similarity in judging mere possibilities, just as we have to rely on them in cognizing the actual world.

Almog, J. 1996. The What and the How II: Reals and Mights. Nô̂s 30, 413-433.

Bealer, G. 2004. The Origins of Modal Error. Dialectica 58, 11-42. 
Biggs, S. 2011. Abduction and Modality. Philosophy and Phenomenological Research 83, 283-326.

Bueno, O., Shalkowski, S. 2015. Modalism and Theoretical Virtues: Toward an Epistemology of Modality. Philosophical Studies 172, 671-89.

Byrne, A. 2007. Possibility and Imagination. Philosophical Perspectives 21, 125-144.

Chalmers, D. 2002. Does Conceivability Entail Possibility?. In Gendler, T.S., Hawthorne, J. (eds.), Conceivability and Possibility, 71-125. Oxford: Clarendon Press.

Chudnoff, E. 2015. Phenomenal Contrast Arguments for Cognitive Phenomenology. Philosophy and Phenomenological Research 91, 82-104.

Day, S.B., Gentner, D. 2007. Non-Intentional Analogical Inference in Text-Comprehension. Memory and Cognition 35, 39-49.

Descartes, R. 1985. The Philosophical Writings of Descartes I. Cambridge: Cambridge University Press.

Evnine, S. 2008. Modal Epistemology: Our Knowledge of Necessity and Possibility. Philosophy Compass 3, 664-684.

Fiocco, M.O. 2007. Conceivability, Imagination and Modal Knowledge. Philosophy and Phenomenological Research 74, 364-380. 
Fischer, E. 2014. Philosophical Intuitions, Heuristics, and Metaphors. Synthese 191, 569-606.

Geirsson, H. 2005. Conceivability and Defeasible Modal Justification. Philosophical Studies $122,279-304$.

Hale, B. 2002. Knowledge of Necessity and Possibility. Proceedings of the Aristotelian Society 103, 1-20.

Hartl, P. 2016. Modal Scepticism, Yablo-Style Conceivability, and Analogical Reasoning. Synthese 193, 269-291.

Hawke, P. 2011. Van Inwagen's Modal Scepticism. Philosophical Studies 153, 351-364.

Hume, D. 1739-40. A Treatise of Human Nature. Selby-Bigge (ed.) [1896]. Oxford: Clarendon Press.

Jackson, F. 2011. On Gettier Holdouts. Mind and Language 26, 468-481.

Jenkins, C. 2010. Concepts, Experience and Modal Knowledge. Philosophical Perspectives $24,255-278$.

Keynes, J.M. 1921. A Treatise on Probability. London: Macmillan.

Kind, A. 2016. Imagining under Constraints. In Kind, A., Kung, P. (eds.), Knowledge Through Imagination, 145-159. Oxford: Oxford University Press. 
Kment, B., 2012. Varieties of Modality. The Stanford Encyclopedia of Philosophy (Winter 2012 Edition), Edward N. Zalta (ed.), URL =

$<$ https://plato.stanford.edu/archives/win2012/entries/modality-varieties/>.

Kment, B. 2014. Modality and Explanatory Reasoning. Oxford: Oxford University Press.

Kriegel, U. 2015. The Varieties of Consciousness. Oxford: Oxford University Press.

Kripke, S. 1980. Naming and Necessity. Cambridge/Mass.: Harvard University Press.

Kung, P. 2010. Imagining as a Guide to Possibility. Philosophy and Phenomenological Research 81, 620-663.

Kung, P. 2016. You Really Do Imagine It: Against Error Theories of Imagination. Nô̂s 50, 90-120.

Leon, F. 2017. From Modal Scepticism to Modal Empiricism. In Fischer, B., Leon, F. (eds.), Modal Epistemology After Rationalism, 247-262. Dordrecht: Synthese Library.

Lewis, D. 1986. Counterfactual Dependence and Time's Arrow, Postscripts to 'Counterfactual Dependence and Times's Arrow'. In Philosophical Papers II, 32-66. Oxford: Oxford University Press.

Lewis, D. 1994. Humean Supervenience Debugged. Mind 103, 473-490. 
Lowe, E.M. 2012. What Is the Source of Our Knowledge of Modal Truths?. Mind 121, 919950.

Morreau, M. 2010. It Simply Doesn't Add Up. Trouble with Comparative Similarity. Journal of Philosophy 107, 469-490.

Peacocke, C. 2004. The Realm of Reason. Oxford: Oxford University Press.

Putnam, H. 1980. Brains and Behavior. In Block, N. (ed.), Readings in Philosophy of Psychology, vol. I, 24-37. London: Methuen.

Rasmussen, J. 2014. Continuity as a Guide to Possibility. Australasian Journal of Philosophy $92,525-538$.

Roca-Royes, S. 2017. Similarity and Possibility: An Epistemology of de re Possibility for Concrete Entities. In Fischer B., Leon, F. (eds.), Modal Epistemology After Rationalism, 22146. Dordrecht: Synthese Library.

Sider, T. 1993. Van Inwagen and the Possibility of Gunk. Analysis 53, 285-289.

Tidman, P. 1994. Conceivability as a test for possibility. American Philosophical Quarterly 31, 297-309.

Van Inwagen, P. 1998. Modal Epistemology. Philosophical Studies 92, 67-84.

Williams, R. 2006. Illusions of Gunk, Philosophical Perspectives 20, 493-513. 
Williamson, T. 2007. The Philosophy of Philosophy. Oxford: Blackwell.

Yablo, S. 1993. Is Conceivability a Guide to Possibility?. Philosophy and Phenomenological Research 53, 1-42.

Yablo, S. 2006. No Fool's Cold. In Garçia-Carpintero, M., Macià, J. (eds.), Two-Dimensional Semantics, 327-345. Oxford: Clarendon Press. 